\title{
Risk of atrial fibrillation in persons with type 2 diabetes and the excess risk in relation to glycaemic control and renal function: a Swedish cohort study
}

\author{
Shilan Seyed Ahmadi ${ }^{12^{*}}$ (D) Ann-Marie Svensson ${ }^{1,3}$, Aldina Pivodic $^{4,5}$, Annika Rosengren ${ }^{1,6}$ and Marcus Lind ${ }^{1,2}$
}

\begin{abstract}
Background: To examine the incidence of atrial fibrillation in individuals with type 2 diabetes compared with ageand sex-matched controls from the general population and its variation in relation to glycaemic control and renal function.

Methods: A total of 421,855 patients with type 2 diabetes from the Swedish National Diabetes Registry and $2,131,223$ controls from the Swedish Population Registry, matched for age, sex and county, were included and followed from January 1, 2001 to December 31, 2013.

Results: Overall, $8.9 \%$ of individuals with type 2 diabetes and $7.0 \%$ of controls were diagnosed with atrial fibrillation during follow-up, unadjusted incidence risk ratio (IRR) 1.35 (95\% 1.33-1.36). Women < 55 years old with type 2 diabetes had an IRR of 2.36 ( $95 \% \mathrm{Cl} 2.10-2.66)$, in relation to controls, whereas the corresponding value for men $<55$ years old with type 2 diabetes was IRR 1.78 (95\% Cl 1.67-1.90). In the fully adjusted Cox regression, the risk of type 2 diabetes on incident atrial fibrillation was $28 \%$ greater vs controls, hazard ratio (HR) 1.28 (95\% Cl 1.26-1.30), $\mathrm{p}<0.0001$. The excess risk of atrial fibrillation in individuals with type 2 diabetes increased with worsening glycaemic control and renal complications. For individuals with $\mathrm{HbA} 1 \mathrm{c} \leq 6.9 \%(\leq 52 \mathrm{mmol} / \mathrm{mol})$ and normoalbuminuria the excess risk vs controls was still increased, adjusted HR 1.16 (95\% Cl 1.14-1.19); $p<0.0001$.

Conclusions: Individuals with type 2 diabetes had an overall $35 \%$ higher risk of atrial fibrillation compared to ageand sex-matched controls from the general population. The excess risk for atrial fibrillation increased with renal complications or with poor glycaemic control. Individuals with type 2 diabetes with good glycaemic control and normoalbuminuria had slightly increased risk.
\end{abstract}

Keywords: Albuminuria, Atrial fibrillation, Glycaemic control, Type 2 diabetes

\section{Background}

Type 2 diabetes is a metabolic disorder, with an increased risk of micro- and macrovascular complications such as thromboembolism, stroke and mortality [1]. At the

\footnotetext{
*Correspondence: shilan.seyed.ahmadi@vgregion.se

${ }^{2}$ Department of Medicine, NU-Hospital Group, Trollhättan/Uddevalla, Sweden

Full list of author information is available at the end of the article
}

same time, atrial fibrillation is the most common cardiac arrhythmia with similar outcomes as type 2 diabetes [2]. The prevalence of both atrial fibrillation and type 2 diabetes has been rising rapidly $[2,3]$. Studies have shown that when both conditions coexist, the risk for thromboembolism is increased [4].

There are conflicting findings on whether type 2 diabetes is an independent risk factor for atrial fibrillation [5-7]. However, several studies have shown that type

c) The Author(s) 2020. This article is licensed under a Creative Commons Attribution 4.0 International License, which permits use, sharing, adaptation, distribution and reproduction in any medium or format, as long as you give appropriate credit to the original author(s) and the source, provide a link to the Creative Commons licence, and indicate if changes were made. The images or other third party material in this article are included in the article's Creative Commons licence, unless indicated otherwise in a credit line to the material. If material is not included in the article's Creative Commons licence and your intended use is not permitted by statutory regulation or exceeds the permitted use, you will need to obtain permission directly from the copyright holder. To view a copy of this licence, visit http://creativeco mmons.org/licenses/by/4.0/. The Creative Commons Public Domain Dedication waiver (http://creativecommons.org/publicdomain/ zero/1.0/) applies to the data made available in this article, unless otherwise stated in a credit line to the data. 
2 diabetes is associated with atrial fibrillation, with risk increasing with poor glycaemic control, glycaemic variability, longer diabetes duration [8], hypertension, and albuminuria [9]. In a meta-analysis, a dose-response relationship was found between increasing blood glucose and risk of atrial fibrillation [10]. Although extensive research has been carried out on the association between type 2 diabetes and atrial fibrillation, few subgroup analyses have been performed on glycaemic control and renal function, with none comparing the risk of atrial fibrillation in subgroups of patients with type 2 diabetes to ageand sex-matched controls from the general population.

Additionally, diabetes is one of the factors included in the risk stratification scheme $\mathrm{CHA}_{2} \mathrm{DS}_{2}-\mathrm{VAS}_{\mathrm{c}}$-score used to identify high-risk patients with atrial fibrillation that may benefit from anticoagulation treatment in order to prevent stroke from thromboembolism [11]. However, guidelines are inadequate regarding recommendations for anticoagulation when both conditions coexist [4]. Hence, increased understanding is needed on how the risk of atrial fibrillation interacts with type 2 diabetes and coexisting diabetes-specific risk factors.

The Swedish National Diabetes Registry (NDR) provides nationwide information on patients with type 2 diabetes. The large size and widespread geographic distribution of the NDR provides unique opportunities to estimate excess risk for atrial fibrillation from both national and international perspectives. The purpose of this study was to examine (a) the incidence of atrial fibrillation in persons with type 2 diabetes and (b) how risk varies in relation to glycaemic control and renal function compared with age- and sex-matched controls from the general population.

\section{Methods}

Ethical approval for this study was obtained from the Regional Ethical Review Board in Gothenburg, Sweden.

\section{Data sources}

We conducted a registry-based cohort study, obtaining data from registries that have nationwide coverage. Clinical data in the NDR are reported from clinical visits in primary care and hospital outpatient clinics regarding risk factors, diabetes-related complications, and medications for individuals with diabetes (type 1 and $2) \geq 18$ years old. Each patient provides informed consent for inclusion in the NDR.

The National Patient Registry (NPR) was used to obtain information on atrial fibrillation, outcomes and co-morbidities and contains records on all admissions to hospitals and outpatient specialist visits, including data such as date of contact, diagnostic, and procedure codes. The population registries and the central bureaus of statistics provided demographic, vital status, and socioeconomic data.

Information about mortality was retrieved from the Swedish Cause of Death Registry. Information about educational level and country of birth was accessed from the Longitudinal Integration Database for Health Insurance and Labor Market Studies. Education level was categorized as low (compulsory education), intermediate, or high (university level education or similar) and country of birth as Sweden or other.

\section{Study population}

Criteria for inclusion in the study were individuals with type 2 diabetes with at least one registration in the NDR. Type 2 diabetes was defined as treatment with either diet or oral antihyperglycemic agents only or diagnosis at $\geq 40$ years of age receiving insulin therapy or insulin and oral antihyperglycemic agents. In total 421,855 individuals with type 2 diabetes were included in the study. For each person, five controls without type 2 diabetes were selected randomly from the Swedish Population Registry matched for age, sex, and county. In total, 2,131,223 controls were selected.

Individuals with type 2 diabetes who died [2688 $(0.10 \%)]$, had atrial fibrillation before January 1, 2001 or before index date [41,547 (1.52\%)] or no NDR visits after January 1, 2001 [7712 (0.28\%)] were excluded (data entry prior to January 1, 1999 was incomplete when comparing care units). Controls who died before January 1, 2001 $[11,427(0.42 \%)]$ or had atrial fibrillation before January 1,2001 or before index date $[121,142(4.43 \%)]$ were also excluded.

\section{Study procedures}

Variables assessed were sex, age, country of birth, educational level, HbA1c (glycated haemoglobin), diabetes duration, BMI (body weight in kilograms divided by height in $\mathrm{m}^{2}$ ), low-density lipoprotein (LDL) cholesterol, systolic and diastolic blood pressure, smoking, renal function (eGFR), and albuminuria.

The incidence of atrial fibrillation was calculated stratified by sex, age group, glycaemic control, and renal function. Glycaemic control was estimated by updated mean HbA1c, which is the mean value of HbA1c measurements up until a certain point in time. Patients were categorized by glycaemic control based on the mean level of HbA1c until a certain time point. HbA1c was measured according to the International Federation of Clinical Chemistry (IFCC) method in $\mathrm{mmol} / \mathrm{mol}$ and converted to levels according to the National Glycohemoglobin Standardization Program for dual reporting.

Renal complications were categorized as normoalbuminuria, microalbuminuria, macroalbuminuria, and 
stage 1-5 chronic kidney disease (CKD). Microalbuminuria was defined as two positive tests from three urine samples taken within 1 year, with an albumin/creatinine ratio of $3-30 \mathrm{mg} / \mathrm{mmol}(\sim 30-300 \mathrm{mg} / \mathrm{g})$ or U-albumin of $20-200 \mu \mathrm{g} / \mathrm{min}(20-300 \mathrm{mg} / \mathrm{L})$, and macroalbuminuria as albumin/creatinine ratio $>30 \mathrm{mg} / \mathrm{mmol}(\sim 300 \mathrm{mg} / \mathrm{g})$ or U-albumin $>200 \mu \mathrm{g} / \mathrm{min}(>300 \mathrm{mg} / \mathrm{L})$. Estimated glomerular filtration rate (eGFR) was calculated using the Chronic Kidney Disease Epidemiology (CKD-EPI) equation [12]. Renal function was categorized as CKD stage 1 (eGFR $\geq 90 \mathrm{~mL} / \mathrm{min}$ ), stage 2 (eGFR $60-89 \mathrm{~mL} / \mathrm{min}$ ), stage 3 (eGFR $30-59 \mathrm{~mL} / \mathrm{min}$ ), stage 4 (eGFR $15-29 \mathrm{~mL} /$ min) and CKD stage 5 (eGFR $<15 \mathrm{~mL} / \mathrm{min}$ or need for renal dialysis).

\section{Study outcome and comorbidities}

The study outcome is atrial fibrillation and flutter, the ICD codes 427D (ICD-9) and I48 (ICD-10), with both primary and secondary diagnosis. International Classification of Disease 9th (ICD-9) and 10th (ICD-10) codes were used to define study comorbidities coronary heart disease, admission for heart failure, valve disease, stroke, and cancer diagnosis before the first and baseline registration (Additional file 1).

\section{Statistical analysis}

Crude event rates were described in total, by age category $(<55,55-64,65-74$ and $>75$ years), and by gender as events per 1000 person-years with 95\% confidence intervals estimated using Poisson regression. The effects of time-updated mean HbA1c categories (mean of all preceding values at each timepoint), time-updated albuminuria categories (last of all preceding values at each timepoint), and time-updated eGFR categories (last of all preceding values at each timepoint) versus the reference group on time to incident atrial fibrillation were analyzed using Cox regression in three different models. In model 1 , adjustments were made for time-updated age and sex. In model 2, adjustments were made for country of birth, education, and baseline comorbidities (coronary heart disease, heart failure, valve disease, stroke and cancer). In model 3, additional adjustments were made for timeupdated diabetes duration. The effects of diabetes group overall and of HbA1c, albuminuria and eGFR categories versus the normal population were obtained for 10th, 25th, 50th, 75th, and 90th percentile of diabetes duration, corresponding to 1, 3, 7, 13 and 19 years. Main analyses were shown for median diabetes duration of 7 years.

In individuals with diabetes, overall and for women and men separately, the association of a $1.0 \%(10 \mathrm{mmol} /$ mol) increase in time-updated mean $\mathrm{HbA1c}$ was evaluated with incidence of atrial fibrillation. Adjustments in models 1,2 , and 3 correspond to the main analyses adjustments. Further adjustments were done in models A, B, C, and D. Model A, adjustment was done for timeupdated mean systolic blood pressure, time-updated mean body mass index, time updated smoking status and time-updated status about blood pressure lowering medication. In model B, adjustments for time-updated mean high-density lipoprotein, time-updated mean lowdensity lipoprotein, time-updated status about lipid lowering medication were done. Model $\mathrm{C}$ were additionally adjusted for time-updated insulin method. In model D, adjustments for time-updated albuminuria categories were done. These analyses have been described earlier [13]. The proportional hazards assumption was checked through visual review of $\log (-\log$ [survival]) versus $\log$ (time) curves.

All tests were two-tailed with $\mathrm{p}$-values $<0.05$ considered significant. All analyses were performed using SAS software version 9.4 (SAS Institute Inc., Cary, NC, USA).

\section{Results \\ Study population}

A total of 421,855 patients with type 2 diabetes and 2,131,223 controls were included. Patient characteristics at baseline are presented in Table 1. Among people with type 2 diabetes, mean age was $64.7 \pm 12.5$ years vs $64.6 \pm 12.5$ years for controls. The mean HbA1c was $7.1 \pm$ $1.4 \%(54.3 \pm 14.9 \mathrm{mmol} / \mathrm{mol})$ with a mean duration of diabetes of $5.4 \pm 7.1$ years. Individuals with high HbA1c values were younger, had a higher mean LDL-level, more frequently smokers, and were more frequently born outside of Sweden.

\section{Excess risk of atrial fibrillation in relation to age and sex}

The mean duration of follow-up was 5.0 years for individuals with type 2 diabetes and 5.3 years for controls. Between January 1, 2001, and December 31, 2013, a total of 37,590 (8.9\%) individuals with type 2 diabetes and $149,231(7.0 \%)$ of controls were diagnosed with atrial fibrillation. Overall, for individuals with type 2 diabetes, the incidence rates of atrial fibrillation were 15.99 cases per 1000 person-years (95\% CI 15.83-16.15) compared to 11.89 cases per 1000 person-years (95\% CI 11.83-11.95) for the control group (Table 2), unadjusted incidence risk ratio (IRR) 1.35 (95\% CI 1.33-1.36). As seen in Table 2, when stratified by age, the incidences rates of atrial fibrillation increased with age for both individuals with type 2 diabetes and controls; however, the relative risk between the two groups decreased with older age.

In Poisson regression analyses, the IRRs for atrial fibrillation in men and women with type 2 diabetes compared to controls were similar, 1.34 vs 1.35 , respectively (Table 2). When stratified by age, the absolute risk for atrial fibrillation was higher for men with type 


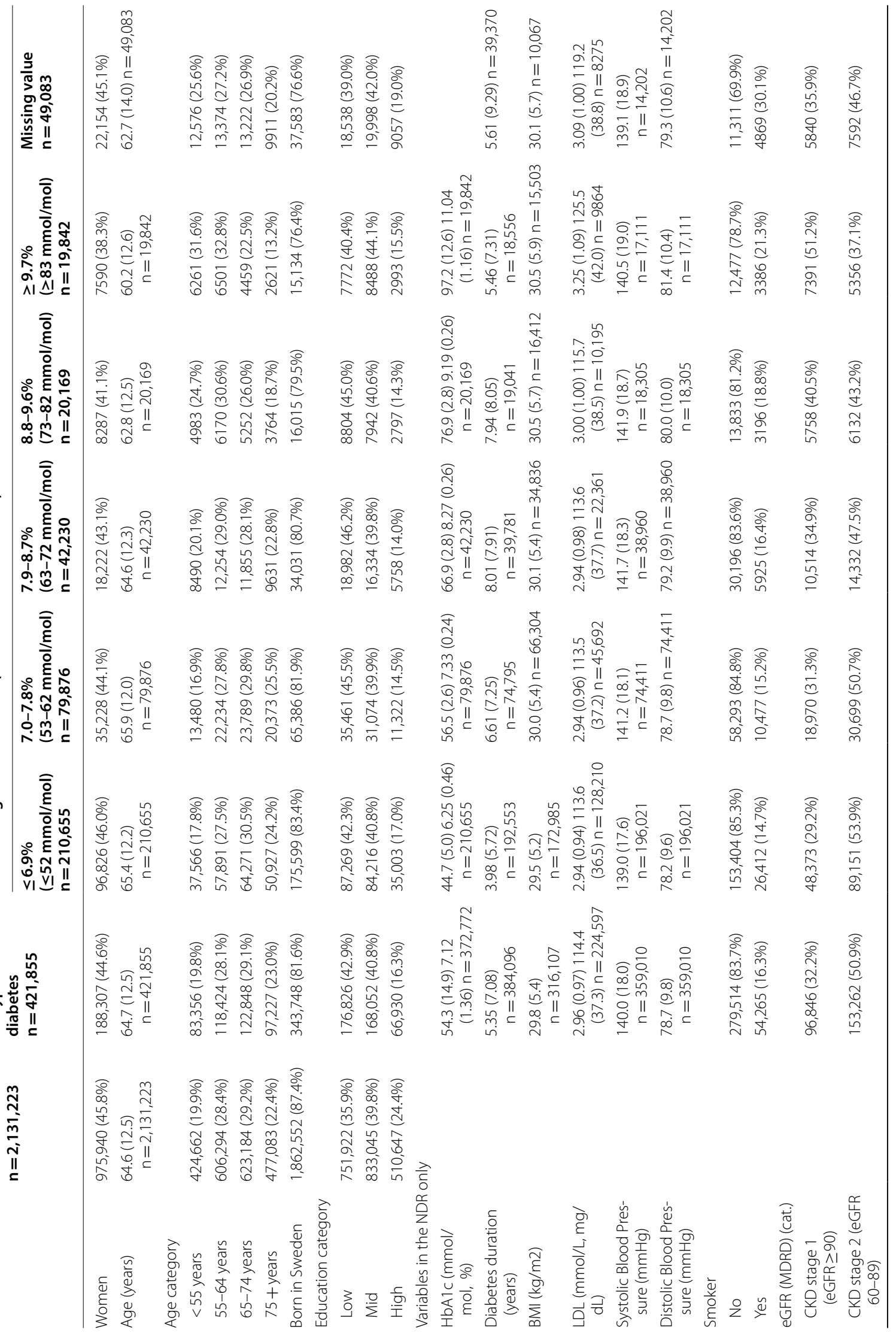




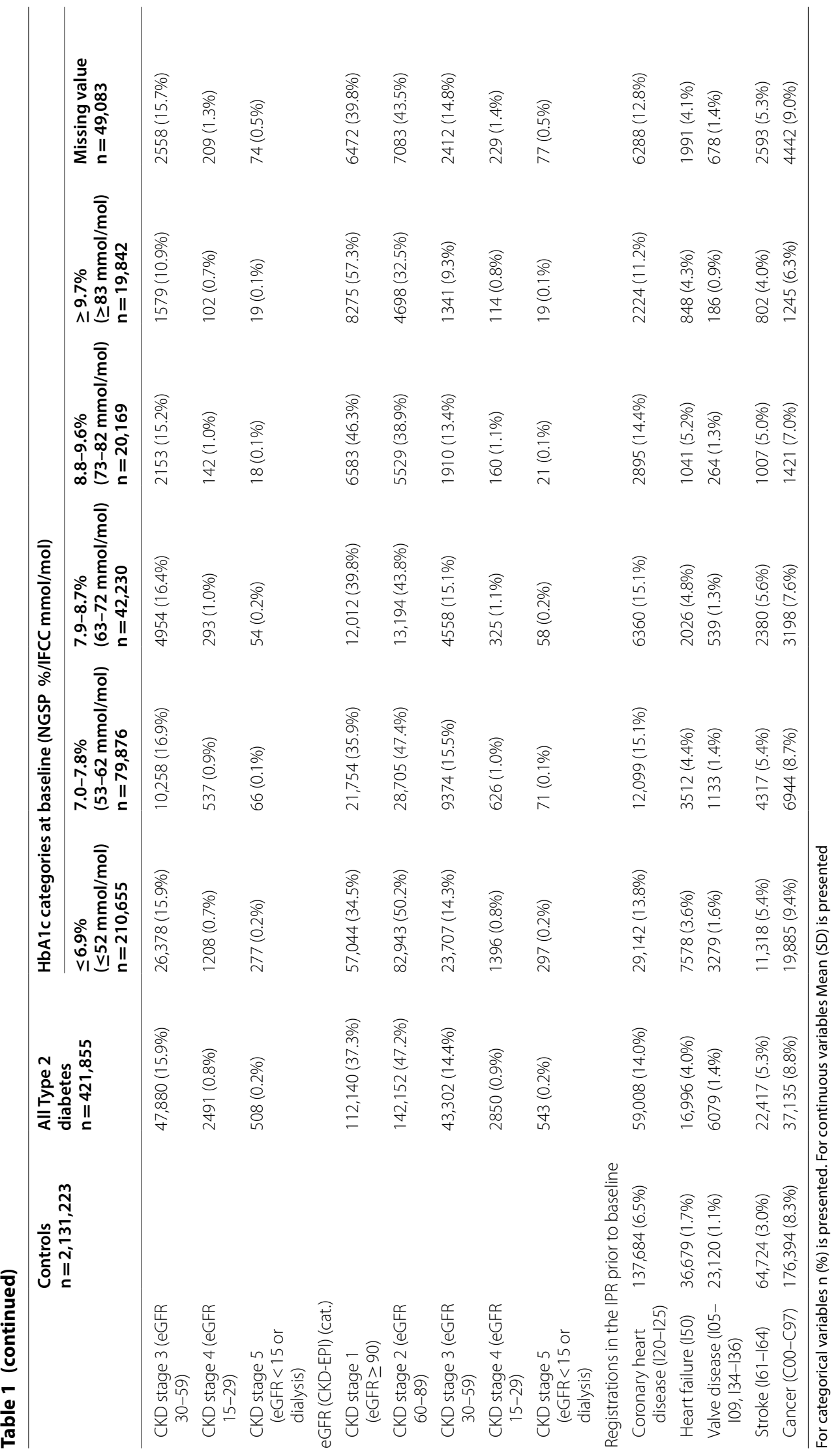


Table 2 Atrial fibrillation per 1000 patient years by sex and age categories at baseline with $95 \%$ confidence intervals estimated by using Poisson regression

\begin{tabular}{|c|c|c|c|c|c|c|}
\hline \multirow{2}{*}{$\begin{array}{l}\text { Atrial fibrillation, any } \\
\text { position }\end{array}$} & \multicolumn{2}{|l|}{ All } & \multicolumn{2}{|l|}{ Men } & \multicolumn{2}{|l|}{ Women } \\
\hline & Type 2 diabetes & Controls & Type 2 diabetes & Controls & Type 2 diabetes & Controls \\
\hline \multicolumn{7}{|l|}{ All } \\
\hline $\mathrm{N}$ & 421,855 & $2,131,223$ & 233,548 & $1,155,283$ & 188,307 & 975,940 \\
\hline n (\%) & $37,590(8.9 \%)$ & $149,231(7.0 \%)$ & 21,808 (9.3\%) & $86,178(7.5 \%)$ & $15,782(8.4 \%)$ & $63,053(6.5 \%)$ \\
\hline $\begin{array}{l}\text { Cases per } 1000 \text { years } \\
(95 \% \mathrm{Cl})\end{array}$ & $15.99(15.83-16.15)$ & $11.89(11.83-11.95)$ & $16.95(16.73-17.18)$ & $12.66(12.58-12.75)$ & $14.83(14.60-15.07)$ & $10.97(10.88-11.05)$ \\
\hline $\begin{array}{l}\text { Unadjusted IRR (95\% } \\
\text { CI) }\end{array}$ & $1.35(1.33-1.36)$ & & $1.34(1.32-1.36)$ & & $1.35(1.33-1.38)$ & \\
\hline \multicolumn{7}{|l|}{$<55$ years } \\
\hline $\mathrm{N}$ & 83,356 & 424,662 & 50,094 & 255,240 & 33,262 & 169,422 \\
\hline n (\%) & 1569 (1.9\%) & $4356(1.0 \%)$ & 1175 (2.3\%) & $3478(1.4 \%)$ & $394(1.2 \%)$ & $878(0.5 \%)$ \\
\hline $\begin{array}{l}\text { Cases per } 1000 \text { years } \\
(95 \% \mathrm{Cl})\end{array}$ & $3.18(3.02-3.34)$ & $1.67(1.62-1.72)$ & $3.96(3.74-4.20)$ & $2.23(2.15-2.30)$ & $1.99(1.80-2.20)$ & $0.84(0.79-0.90)$ \\
\hline $\begin{array}{l}\text { Unadjusted IRR (95\% } \\
\text { CI) }\end{array}$ & $1.90(1.79-2.01)$ & & $1.78(1.67-1.90)$ & & $2.36(2.10-2.66)$ & \\
\hline \multicolumn{7}{|l|}{$55-64$ years } \\
\hline $\mathrm{N}$ & 118,424 & 606,294 & 72,337 & 371,480 & 46,087 & 234,814 \\
\hline n (\%) & $6819(5.8 \%)$ & $22,332(3.7 \%)$ & $4901(6.8 \%)$ & $16,729(4.5 \%)$ & 1918 (4.2\%) & $5603(2.4 \%)$ \\
\hline $\begin{array}{l}\text { Cases per } 1000 \text { years } \\
(95 \% \mathrm{Cl})\end{array}$ & $9.50(9.28-9.73)$ & $5.84(5.77-5.92)$ & $11.30(10.99-11.62)$ & $7.20(7.09-7.31)$ & $6.75(6.46-7.06)$ & $3.74(3.64-3.84)$ \\
\hline $\begin{array}{l}\text { Unadjusted IRR (95\% } \\
\text { CI) }\end{array}$ & $1.63(1.58-1.67)$ & & $1.57(1.52-1.62)$ & & $1.81(1.71-1.90)$ & \\
\hline \multicolumn{7}{|l|}{$65-74$ years } \\
\hline $\mathrm{N}$ & 122,848 & 623,184 & 67,666 & 335,590 & 55,182 & 287,594 \\
\hline n (\%) & $12,973(10.6 \%)$ & $50,919(8.2 \%)$ & $8011(11.8 \%)$ & $32,223(9.6 \%)$ & 4962 (9.0\%) & $18,696(6.5 \%)$ \\
\hline $\begin{array}{l}\text { Cases per } 1000 \text { years } \\
(95 \% \mathrm{Cl})\end{array}$ & 18.99 (18.67-19.32) & $13.75(13.63-13.87)$ & $22.10(21.62-22.59)$ & $16.54(16.36-16.72)$ & $15.47(15.05-15.91)$ & $10.65(10.50-10.80)$ \\
\hline $\begin{array}{l}\text { Unadjusted IRR (95\% } \\
\text { CI) }\end{array}$ & $1.38(1.36-1.41)$ & & $1.34(1.30-1.37)$ & & $1.45(1.41-1.50)$ & \\
\hline \multicolumn{7}{|l|}{$75+$ years } \\
\hline N & 97,227 & 477,083 & 43,451 & 192,973 & 53,776 & 284,110 \\
\hline n (\%) & $16,229(16.7 \%)$ & $71,624(15.0 \%)$ & 7721 (17.8\%) & $33,748(17.5 \%)$ & $8508(15.8 \%)$ & $37,876(13.3 \%)$ \\
\hline $\begin{array}{l}\text { Cases per } 1000 \text { years } \\
(95 \% \mathrm{Cl})\end{array}$ & $35.62(35.08-36.17)$ & $29.54(29.33-29.76)$ & 39.76 38.88-40.66) & $34.82(34.45-35.20)$ & $32.54(31.86-33.24)$ & $26.02(25.76-26.29)$ \\
\hline $\begin{array}{l}\text { Unadjusted IRR (95\% } \\
\text { CI) }\end{array}$ & $1.21(1.19-1.23)$ & & $1.14(1.11-1.17)$ & & $\begin{array}{l}1.25 \\
(1.22-1.28)\end{array}$ & \\
\hline
\end{tabular}

2 diabetes, but the relative risk was greater for women with type 2 diabetes compared to their matched controls. For men, incidence rates of atrial fibrillation for patients with type 2 diabetes were 16.95 cases per 1000 person-years (95\% CI 16.73-17.18) and for controls 12.66 cases per 1000 person-years (95\% CI 12.58-12.75). For women, the corresponding values were 14.83 cases per 1000 years (95\% CI 14.60-15.07) vs controls 10.97 cases per 1000 person-years (95\% CI 10.88-11.05). The unadjusted IRRs for men with type 2 diabetes aged $<55$ years old were 1.78 (95\% CI 1.67-1.90) and for men $>75$ years old the IRR was reduced to 1.14 (95\% CI 1.11-1.17) compared to controls. For women, the corresponding estimates were 2.36 (95\% CI 2.102.66 ) and 1.25 (95\% CI $1.22-1.28$ ), respectively, compared to controls.

The excess risk for atrial fibrillation was evaluated in relation to diabetes duration, and effects were evaluated for median diabetes duration of 7 years (Additional file 1: Table S1). In model 1, the incidences for atrial fibrillation were adjusted for time-updated age and sex. For individuals with type 2 diabetes, the HR was 1.37 (95\% CI 1.35-1.38), $\mathrm{p}<0.0001$ compared to controls. When further adjustment for country of birth, education and baseline comorbidities was performed (model 2), the HR decreased to 1.30 (95\% CI 1.28-1.31), p $<0.0001$ 
compared to controls. In model 3, with additional adjustments for time-updated diabetes duration, the HR decreased to 1.28 (95\% CI 1.26-1.30), $\mathrm{p}<0.0001$ compared to controls. Corresponding estimates of risk for atrial fibrillation stratified by sex are shown in Additional file 1: Table S1. In model 3, women with type 2 diabetes had an HR of 1.31 (95\% CI 1.28-1.34) compared to controls, whereas the corresponding value for men with type 2 diabetes was 1.26 (95\% 1.24-1.28). For individuals with type 2 diabetes, the HR per 10-year increase for timeupdated diabetes duration was 1.03 (95\% CI 1.02-1.05); $\mathrm{p}<0.0001$ for all, 1.04 (95\% CI 1.02-1.06); $\mathrm{p}<0.0001$ for men and for women 1.02 (95\% CI 1.00-1.05); $\mathrm{p}=0.068$.
Excess risk for atrial fibrillation for time-updated mean $\mathrm{HbA1c}$, albuminuria, and eGFR categories

Table 3 displays the risk of atrial fibrillation by categories of time-updated $\mathrm{HbA} 1 \mathrm{c}$, albuminuria, and eGFR adjusted according to model 3 in individuals with type 2 diabetes versus controls. There was a significant excess risk with increasing HbA1c and albuminuria. The increased risk was also present for individuals with type 2 diabetes and good glycaemic control or normoalbuminuria, with HRs of 1.24 (95\% CI 1.22-1.26), $\mathrm{p}<0.0001$, and 1.17 (95\% CI 1.16-1.19), $\mathrm{p}<0.0001$, compared to controls, respectively. The corresponding values from models 1 and 2 and for men and women, respectively, are found in Additional file 1: Table S2 and S3.

Table 3 Adjusted hazard ratios for atrial fibrillation and 95\% confidence intervals for time-updated mean HbA1c categories, albuminuria categories and eGFR categories versus the reference group examined by Cox regression

\begin{tabular}{|c|c|c|c|}
\hline \multirow[t]{2}{*}{ Atrial fibrillation } & \multicolumn{3}{|l|}{$\begin{array}{l}\text { Hazard ratio }(95 \% \mathrm{Cl}) \\
p \text { value }\end{array}$} \\
\hline & Model 1 & Model 2 & Model 3 \\
\hline Time updated mean $\mathrm{HbA} 1 \mathrm{c}$ categories & $\begin{array}{l}n \text { events }=185,793 \\
N \text { subjects }=2,544,103 \\
\text { data used }=99.6 \%\end{array}$ & $\begin{array}{l}\mathrm{n} \text { events }=182,081 \\
N \text { subjects }=2,498,727 \\
\text { data used }=97.9 \%\end{array}$ & $\begin{array}{l}\text { n events }=179,445 \\
N \text { subjects }=2,465,540 \\
\text { data used }=96.6 \%\end{array}$ \\
\hline Controls (reference) & 1.00 & 1.00 & 1.00 \\
\hline$\leq 6.9 \%(\leq 52 \mathrm{mmol} / \mathrm{mol})$ & $1.32(1.30-1.34)<0.0001$ & $1.26(1.24-1.27)<0.0001$ & $1.24(1.22-1.26)<0.0001$ \\
\hline $7.0-7.8 \%$ (53-62 mmol/mol) & $1.36(1.34-1.39)<0.0001$ & $1.29(1.27-1.32)<0.0001$ & $1.28(1.25-1.31)<0.0001$ \\
\hline 7.9-8.7\% (63-72 mmol/mol) & $1.47(1.43-1.52)<0.0001$ & $1.38(1.34-1.42)<0.0001$ & $1.38(1.34-1.42)<0.0001$ \\
\hline $8.8-9.6 \%(73-82 \mathrm{mmol} / \mathrm{mol})$ & $1.61(1.54-1.69)<0.0001$ & $1.49(1.42-1.57)<0.0001$ & $1.47(1.40-1.55)<0.0001$ \\
\hline$\geq 9.7 \%(\geq 83 \mathrm{mmol} / \mathrm{mol})$ & $1.65(1.55-1.77)<0.0001$ & $1.56(1.46-1.68)<0.0001$ & $1.57(1.46-1.68)<0.0001$ \\
\hline Time updated albuminuria categories & $\begin{array}{l}\mathrm{n} \text { events }=179,380 \\
\mathrm{~N} \text { subjects }=2,473,810 \\
\text { Data used }=96.9 \%\end{array}$ & $\begin{array}{l}\text { n events }=175,890 \\
N \text { subjects }=2,431,009 \\
\text { Data used }=95.2 \%\end{array}$ & $\begin{array}{l}\mathrm{n} \text { events }=174,059 \\
\mathrm{~N} \text { subjects }=2,409,479 \\
\text { Data used }=94.4 \%\end{array}$ \\
\hline Controls (reference) & 1.00 & 1.00 & 1.00 \\
\hline Normoalbuminuria & $1.24(1.22-1.25)<0.0001$ & $1.18(1.17-1.20)<0.0001$ & $1.17(1.16-1.19)<0.0001$ \\
\hline Microalbuminuria & $1.63(1.59-1.67)<0.0001$ & $1.54(1.50-1.58)<0.0001$ & $1.52(1.48-1.56)<0.0001$ \\
\hline Macroalbuminuria & $1.91(1.85-1.97)<0.0001$ & $1.75(1.69-1.80)<0.0001$ & $1.74(1.68-1.80)<0.0001$ \\
\hline CKD stage 5 & $3.73(3.32-4.20)<0.0001$ & $3.23(2.87-3.64)<0.0001$ & $\begin{array}{l}3.24(2.86-3.66) \\
<0.0001\end{array}$ \\
\hline Time updated eGFR categories & $\begin{array}{l}\mathrm{n} \text { events }=183,107 \\
\mathrm{~N} \text { subjects }=2,525,557 \\
\text { Data used }=98.9 \%\end{array}$ & $\begin{array}{l}\mathrm{n} \text { events }=179,482 \\
\mathrm{~N} \text { subjects }=2,481,018 \\
\text { Data used }=97.2 \%\end{array}$ & $\begin{array}{l}\text { n events }=176,958 \\
\mathrm{~N} \text { subjects }=2,449,089 \\
\text { Data used }=95.9 \%\end{array}$ \\
\hline Controls (reference) & 1.00 & 1.00 & 1.00 \\
\hline CKD stage 1 (eGFR $\geq 90)$ & $1.38(1.34-1.42)<0.0001$ & $1.35(1.31-1.39)<0.0001$ & $1.33(1.29-1.37)<0.0001$ \\
\hline CKD stage 2 (eGFR 60-89) & $1.28(1.26-1.30)<0.0001$ & $1.23(1.21-1.25)<0.0001$ & $1.22(1.20-1.24)<0.0001$ \\
\hline CKD stage 3 (eGFR 30-59) & $1.47(1.44-1.50)<0.0001$ & $1.34(1.32-1.37)<0.0001$ & $1.33(1.30-1.36)<0.0001$ \\
\hline CKD stage 4 (eGFR 15-29) & $2.09(1.98-2.21)<0.0001$ & $1.78(1.68-1.88)<0.0001$ & $1.76(1.66-1.87)<0.0001$ \\
\hline CKD stage 5 (eGFR $<15$ or dialysis) & $3.77(3.36-4.25)<0.0001$ & $3.27(2.91-3.69)<0.0001$ & $3.24(2.87-3.67)<0.0001$ \\
\hline
\end{tabular}

Model 1: adjusted for time-updated age and sex

Model 2: model 1 additionally adjusted for born in Sweden, maximum education level and baseline comorbidities (CHD, HF, VD, stroke, cancer)

Model 3: model 2 additionally adjusted for time-updated diabetes duration (effects taken for DD $=7$ years [median]) 
Excess risk for atrial fibrillation related to time-updated mean $\mathrm{HbA1c}$ together with albuminuria and eGFR

In Table 4 the excess risk of atrial fibrillation was evaluated in relation to $\mathrm{HbA1c}$ for presence/absence of albuminuria versus controls. Individuals with $\mathrm{HbA1c} \leq 6.9 \%$ $(\leq 52 \mathrm{mmol} / \mathrm{mol})$ and normoalbuminuria had an HR of 1.16 (95\% CI 1.14-1.19) compared to controls. The corresponding value for individuals with $\mathrm{HbAlc} \geq 9.7 \%$ $(\geq 83 \mathrm{mmol} / \mathrm{mol})$ and normoalbuminuria was 1.35 (95\% CI 1.20-1.52). Corresponding HRs were 1.55 (95\% $1.50-1.60)$ and 2.04 (95\% CI 1.82-2.28) vs controls for individuals with $\mathrm{HbA} 1 \mathrm{c} \leq 6.9 \%(\leq 52 \mathrm{mmol} / \mathrm{mol})$ and $\geq 9.7 \%$ ( $\geq 83 \mathrm{mmol} / \mathrm{mol}$ ) with albuminuria, respectively. This was also evaluated in men and women separately (Additional file 1: Table S4 and S5). An increasing excess risk versus controls for men and women was noted with higher time-updated mean $\mathrm{HbA1c}$ for patients with normoalbuminuria, albuminuria as well as within different eGFR categories.

\section{Risk of atrial fibrillation by $10 \mathrm{mmol} / \mathrm{mol}$ higher mean HbA1c in persons with type 2 diabetes}

Additionally, the risk of atrial fibrillation was estimated in relation to $1.0 \%(10.0 \mathrm{mmol} / \mathrm{mol})$ higher mean $\mathrm{HbA} 1 \mathrm{c}$ in individuals with type 2 diabetes (Table 5). For individuals with type 2 diabetes, HRs varied between 1.01 and 1.04 in stepwise adjustments for birth in Sweden, education level, baseline comorbidities, and time-updated diabetes duration. When stratified for sex, the risk of atrial fibrillation in men increased by 1.01 (95\% CI 1.00-1.03), $\mathrm{p}=0.04$, and 1.04 (95\% CI 1.03-1.06), $\mathrm{p}<0.0001$, in women. Further analyses on the impact of time-updated mean $\mathrm{HbA1c}$ categories on time to first atrial fibrillation among individuals with type 2 diabetes stratified by sex are shown in Additional file 1: Tables S6 and S7.

\section{Discussion}

This large population-based cohort study showed a 35\% increased risk of atrial fibrillation in individuals with type 2 diabetes in comparison to matched controls from the general population. The excess risk increased with poorer glycaemic control and severity of renal complications. In individuals with type 2 diabetes, good glycaemic control, and normoalbuminuria, there was a slight yet significantly increased excess risk. The absolute risk of atrial fibrillation was higher for men with type 2 diabetes, but the relative risk was greater for women with type 2 diabetes compared to controls. Women $<55$ years with type 2 diabetes had a twofold increased risk, and individuals with type 2 diabetes and CKD stage 5 had a threefold increased risk for atrial fibrillation compared to controls. Additionally, the increased risk of atrial fibrillation in relation to $1.0 \%(10 \mathrm{mmol} / \mathrm{mol})$ higher mean HbA1c evaluated in persons with diabetes was estimated to range from 1.0 to $4.0 \%$.

Our study is in line with others demonstrating the positive association between diabetes and the risk of atrial fibrillation. In two different meta-analyses including both observational and cohort studies, it was concluded that individuals with type 2 diabetes had a $30.0-40.0 \%$ increased risk of atrial fibrillation, even after adjustments for BMI, smoking, hypertension, kidney disease, coronary heart disease, and hyperthyroidism [10, 14]. In our study, women aged $<55$ years with type 2 diabetes had an excess risk of atrial fibrillation (HR 2.36) compared to controls, whereas the HR in men in the same age group was 1.78 compared to controls. Older patients with type 2 diabetes had a lower excess but higher absolute risk of atrial fibrillation. A similar pattern was seen in individuals with type 1 diabetes in a previously published cohort study from Sweden [13]. Additionally, a Danish cohort study reported that the risk of atrial fibrillation in individuals with type 2 diabetes was most pronounced in younger patients [15]. When analyzing the excess risk of atrial fibrillation in relation to renal complications, an increased excess risk of atrial fibrillation was observed with greater albuminuria and eGFR. Likewise, in earlier analyses, it has been proposed that hypertension, greater $\mathrm{BMI}$, and albuminuria are risk factors associated with the development of atrial fibrillation in individuals with type 2 diabetes $[9,16,17]$. A study in a Japanese cohort indicated that albuminuria was significantly associated with cardiovascular events and death compared to individuals with type 2 diabetes without renal failure [18]. Additionally, in a large general practice cohort in the United Kingdom including patients with insulin-treated type 2 diabetes, a regression in albuminuria associated with a significant reduction in all-cause mortality was observed [19]. To our knowledge, this is the first study of the excess risk of atrial fibrillation for different HbA1c categories in relation to renal function in comparison with the general population.

Although one should be cautious to make direct comparisons between different studies, it is of interest to notice that the excess risk of heart failure [20], major coronary heart events [21] and stroke [22] has been evaluated in individuals with type 2 diabetes compared to controls from similar cohorts as the current based on the Swedish Diabetes Register. Current together with earlier results therefore give indications how incidences and relative risks differ for various cardiovascular complications. Among individuals with type 2 diabetes, 11.9 cases per 1000 person-years were hospitalized with a diagnosis of heart failure, compared with 
Table 4 Adjusted hazard ratios for atrial fibrillation and $95 \%$ confidence intervals for time-updated mean $\mathrm{HbA1c}$ categories together with albuminuria and eGFR versus the reference group examined by Cox regression

\begin{tabular}{|c|c|c|c|}
\hline \multirow[t]{2}{*}{ Atrial fibrillation } & \multicolumn{3}{|l|}{$\begin{array}{l}\text { Hazard ratio }(95 \% \mathrm{Cl}) \\
\text { p-value }\end{array}$} \\
\hline & Model 1 & Model 2 & Model 3 \\
\hline Time updated mean HbA1c categories and albuminuria & $\begin{array}{l}\mathrm{n} \text { events }=179,166 \\
\mathrm{~N} \text { subjects }=2,471,982 \\
\text { Data used }=96.8 \%\end{array}$ & $\begin{array}{l}\mathrm{n} \text { events }=175,683 \\
\mathrm{~N} \text { subjects }=2,429,261 \\
\text { Data used }=95.2 \%\end{array}$ & $\begin{array}{l}\mathrm{n} \text { events }=173,899 \\
\mathrm{~N} \text { subjects }=2,408,243 \\
\text { Data used }=94.3 \%\end{array}$ \\
\hline Controls (reference) & 1.00 & 1.00 & 1.00 \\
\hline$\leq 6.9 \%(\leq 52 \mathrm{mmol} / \mathrm{mol})$-normoalbuminuria & $1.22(1.20-1.24)<0.0001$ & $1.17(1.15-1.20)<0.0001$ & $1.16(1.14-1.19)<0.0001$ \\
\hline 7.0-7.8\% (53-62 mmol/mol)-normoalbuminuria & $1.22(1.19-1.25)<0.0001$ & $1.16(1.13-1.20)<0.0001$ & $1.16(1.13-1.19)<0.0001$ \\
\hline 7.9-8.7\% (63-72 mmol/mol)-normoalbuminuria & $1.30(1.24-1.35)<0.0001$ & $1.23(1.17-1.28)<0.0001$ & $1.24(1.18-1.29)<0.0001$ \\
\hline 8.8-9.6\% (73-82 mmol/mol)-Normoalbuminuria & $1.40(1.30-1.51)<0.0001$ & $1.32(1.23-1.43)<0.0001$ & $1.31(1.21-1.42)<0.0001$ \\
\hline$\geq 9.7 \%(\geq 83 \mathrm{mmol} / \mathrm{mol})$-normoalbuminuria & $1.43(1.28-1.61)<0.0001$ & $1.35(1.20-1.51)<0.0001$ & $1.35(1.20-1.52)<0.0001$ \\
\hline$\leq 6.9 \%(\leq 52 \mathrm{mmol} / \mathrm{mol})-$ Not normoalbuminuria & $1.68(1.63-1.73)<0.0001$ & $1.56(1.52-1.61)<0.0001$ & $1.55(1.50-1.60)<0.0001$ \\
\hline 7.0-7.8\% (53-62 mmol/mol)-Not normoalbuminuria & $1.72(1.67-1.79)<0.0001$ & $1.62(1.56-1.67)<0.0001$ & $1.61(1.55-1.67)<0.0001$ \\
\hline 7.9-8.7\% (63-72 mmol/mol)-Not normoalbuminuria & $1.86(1.77-1.95)<0.0001$ & $1.72(1.64-1.81)<0.0001$ & $1.73(1.64-1.82)<0.0001$ \\
\hline 8.8-9.6\% (73-82 mmol/mol)-Not normoalbuminuria & $2.04(1.90-2.20)<0.0001$ & $1.85(1.71-1.99)<0.0001$ & $1.85(1.71-2.00)<0.0001$ \\
\hline$\geq 9.7 \%(\geq 83 \mathrm{mmol} / \mathrm{mol})-$ Not normoalbuminuria & $2.20(1.97-2.45)<0.0001$ & $2.00(1.79-2.23)<0.0001$ & $2.04(1.82-2.28)<0.0001$ \\
\hline Time updated mean $\mathrm{HbA} 1 \mathrm{c}$ categories and eGFR & $\begin{array}{l}\mathrm{n} \text { events }=182,743 \\
\mathrm{~N} \text { subjects }=2,522,210 \\
\text { Data used }=98.8 \%\end{array}$ & $\begin{array}{l}\mathrm{n} \text { events }=179,127 \\
\mathrm{~N} \text { subjects }=2,477,785 \\
\text { Data used }=97.1 \%\end{array}$ & $\begin{array}{l}\mathrm{n} \text { events }=176,733 \\
\mathrm{~N} \text { subjects }=2,447,085 \\
\text { Data used }=95.8 \%\end{array}$ \\
\hline Controls (reference) & 1.00 & 1.00 & 1.00 \\
\hline$\leq 6.9 \%(\leq 52 \mathrm{mmol} / \mathrm{mol})-\mathrm{eGFR} \geq 60$ & $1.26(1.24-1.29)<0.0001$ & $1.22(1.20-1.25)<0.0001$ & $1.21(1.19-1.24)<0.0001$ \\
\hline $7.0-7.8 \%(53-62 \mathrm{mmol} / \mathrm{mol})-\mathrm{eGFR} \geq 60$ & $1.29(1.26-1.32)<0.0001$ & $1.24(1.21-1.28)<0.0001$ & $1.24(1.20-1.27)<0.0001$ \\
\hline $7.9-8.7 \%(63-72 \mathrm{mmol} / \mathrm{mol})-\mathrm{eGFR} \geq 60$ & $1.38(1.33-1.44)<0.0001$ & $1.33(1.27-1.38)<0.0001$ & $1.33(1.27-1.39)<0.0001$ \\
\hline $8.8-9.6 \%(73-82 \mathrm{mmol} / \mathrm{mol})-\mathrm{eGFR} \geq 60$ & $1.51(1.41-1.61)<0.0001$ & $1.43(1.34-1.53)<0.0001$ & $1.41(1.32-1.52)<0.0001$ \\
\hline$\geq 9.7 \%(\geq 83 \mathrm{mmol} / \mathrm{mol})-\mathrm{eGFR}>=60$ & $1.55(1.42-1.71)<0.0001$ & $\begin{array}{l}1.51(1.38-1.66) \\
<0.0001\end{array}$ & $1.52(1.38-1.68)<0.0001$ \\
\hline$\leq 6.9 \%(\leq 52 \mathrm{mmol} / \mathrm{mol})-\mathrm{eGFR}<60$ & $1.45(1.42-1.49)<0.0001$ & $1.33(1.30-1.37)<0.0001$ & $1.32(1.28-1.36)<0.0001$ \\
\hline 7.0-7.8\% (53-62 mmol/mol)-eGFR<60 & $1.54(1.49-1.60)<0.0001$ & $1.41(1.36-1.46)<0.0001$ & $1.40(1.35-1.45)<0.0001$ \\
\hline 7.9-8.7\% (63-72 mmol/mol)-eGFR<60 & $1.73(1.65-1.81)<0.0001$ & $1.55(1.47-1.62)<0.0001$ & $1.56(1.48-1.65)<0.0001$ \\
\hline 8.8-9.6\% (73-82 mmol/mol)-eGFR<60 & $\begin{array}{l}1.87(1.72-2.03) \\
<0.0001\end{array}$ & $\begin{array}{l}1.64(1.51-1.79) \\
<0.0001\end{array}$ & $\begin{array}{l}1.65(1.51-1.80) \\
<0.0001\end{array}$ \\
\hline$\geq 9.7 \%(\geq 83 \mathrm{mmol} / \mathrm{mol})-\mathrm{eGFR}<60$ & $\begin{array}{l}1.98(1.74-2.25) \\
<0.0001\end{array}$ & $\begin{array}{l}1.71(1.50-1.95) \\
<0.0001\end{array}$ & $\begin{array}{l}1.75(1.53-2.00) \\
<0.0001\end{array}$ \\
\hline Time updated mean HbA1c categories albuminuria and eGFR & $\begin{array}{l}\mathrm{n} \text { events }=179,980 \\
\mathrm{~N} \text { subjects }=2,480,217 \\
\text { Data used }=97.1 \%\end{array}$ & $\begin{array}{l}\mathrm{n} \text { events }=176,459 \\
\mathrm{~N} \text { subjects }=2,437,158 \\
\text { Data used }=95.5 \%\end{array}$ & $\begin{array}{l}\mathrm{n} \text { events }=174,466 \\
\mathrm{~N} \text { subjects }=2,414,092 \\
\text { Data used }=94.6 \%\end{array}$ \\
\hline Controls (reference) & 1.00 & 1.00 & 1.00 \\
\hline$\leq 6.9 \%(\leq 52 \mathrm{mmol} / \mathrm{mol})-$ Normoalbuminuria and eGFR $\geq 60$ & $1.19(1.16-1.22)<0.0001$ & $\begin{array}{l}1.16(1.13-1.19) \\
<0.0001\end{array}$ & $\begin{array}{l}1.15(1.12-1.18) \\
<0.0001\end{array}$ \\
\hline 7.0-7.8\% (53-62 mmol/mol)-Normoalbuminuria and eGFR $\geq 60$ & $1.17(1.14-1.21)<0.0001$ & $1.14(1.10-1.18)<0.0001$ & $1.13(1.09-1.17)<0.0001$ \\
\hline 7.9-8.7\% (63-72 mmol/mol)-Normoalbuminuria and eGFR $\geq 60$ & $1.22(1.16-1.29)<0.0001$ & $1.17(1.11-1.24)<0.0001$ & $1.19(1.13-1.26)<0.0001$ \\
\hline $8.8-9.6 \%(73-82 \mathrm{mmol} / \mathrm{mol})-$ Normoalbuminuria and eGFR $\geq 60$ & $1.30(1.18-1.43)<0.0001$ & $1.25(1.14-1.38)<0.0001$ & $1.25(1.13-1.38)<0.0001$ \\
\hline$\geq 9.7 \%(\geq 83 \mathrm{mmol} / \mathrm{mol})-$ Normoalbuminuria and eGFR $\geq 60$ & $1.40(1.22-1.62)<0.0001$ & $1.35(1.16-1.56)<0.0001$ & $1.33(1.14-1.55)<0.0002$ \\
\hline$\leq 6.9 \%(\leq 52 \mathrm{mmol} / \mathrm{mol})-$ Not Normoalbuminuria or eGFR $<60$ & $1.50(1.47-1.53)<0.0001$ & $1.39(1.36-1.42)<0.0001$ & $1.38(1.34-1.41)<0.0001$ \\
\hline 7.0-7.8\% (53-62 mmol/mol)-Not Normoalbuminuria or eGFR < 60 & $1.57(1.52-1.61)<0.0001$ & $1.45(1.41-1.49)<0.0001$ & $1.45(1.41-1.50)<0.0001$ \\
\hline 7.9-8.7\% (63-72 mmol/mol)-Not Normoalbuminuria or eGFR < 60 & $1.75(1.68-1.81)<0.0001$ & $1.60(1.54-1.66)<0.0001$ & $1.61(1.55-1.68)<0.0001$ \\
\hline $8.8-9.6 \%(73-82 \mathrm{mmol} / \mathrm{mol})-$ Not Normoalbuminuria or eGFR $<60$ & $1.90(1.79-2.03)<0.0001$ & $1.71(1.60-1.82)<0.0001$ & $1.72(1.61-1.84)<0.0001$ \\
\hline$\geq 9.7 \%(\geq 83 \mathrm{mmol} / \mathrm{mol})-$ Not Normoalbuminuria or eGFR $<60$ & $2.03(1.85-2.23)<0.0001$ & $1.84(1.67-2.02)<0.0001$ & $1.88(1.71-2.08)<0.0001$ \\
\hline
\end{tabular}

Model 1: adjusted for time-updated age and sex

Model 2: model 1 additionally adjusted for born in Sweden, maximum education level and baseline comorbidities (CHD, HF, VD, stroke, cancer) Model 3: model 2 additionally adjusted for time-updated diabetes duration 
Table 5 Type 2 diabetes only-all-risk for atrial fibrillation by $1.0 \%(10 \mathrm{mmol} / \mathrm{mol})$ of time updated mean $\mathrm{HbA1c}$

\begin{tabular}{lrrll}
\hline & P-value & HR & Lower 95\% Cl & Upper 95\% Cl \\
\hline Overall & & & & \\
Model 1 & $<0.0001$ & 1.038 & 1.029 & 1.048 \\
Model 2 & $<0.0001$ & 1.030 & 1.021 & 1.039 \\
Model 3 & $<0.0001$ & 1.027 & 1.017 & 1.037 \\
Model 3A & $<0.0001$ & 1.010 & 0.999 & 1.021 \\
Model 3B & $<0.0001$ & 1.031 & 1.018 & 1.043 \\
Model 3C & $<0.0001$ & 1.023 & 1.005 & 1.041 \\
Model 3D & $<0.0001$ & 1.013 & 1.002 & 1.025 \\
Male & & & & \\
Model 1 & $<0.0001$ & 1.026 & 1.014 & 1.038 \\
Model 2 & 0.0024 & 1.019 & 1.007 & 1.031 \\
Model 3 & 0.0443 & 1.013 & 1.000 & 1.027 \\
Model 3A & 0.4609 & 0.995 & 0.981 & 1.009 \\
Model 3B & 0.0070 & 1.022 & 1.006 & 1.037 \\
Model 3C & 0.1571 & 1.017 & 0.994 & 1.040 \\
Model 3D & 0.4320 & 0.994 & 0.980 & 1.009 \\
Female & & & & \\
Model 1 & $<0.0001$ & 1.054 & 1.039 & 1.068 \\
Model 2 & $<0.0001$ & 1.044 & 1.030 & 1.059 \\
Model 3 & $<0.0001$ & 1.044 & 1.028 & 1.060 \\
Model 3A & 0.0012 & 1.029 & 1.011 & 1.047 \\
Model 3B & $<0.0001$ & 1.043 & 1.023 & 1.063 \\
Model 3C & 0.0244 & 1.033 & 1.004 & 1.063 \\
Model 3D & $<0.0001$ & 1.040 & 1.022 & 1.058 \\
\hline Model1: adfused fort & &
\end{tabular}

Model 1: adjusted for time-updated age

Model 2: model 1 additionally adjusted for born in Sweden, education level, baseline comorbidities (coronary heart disease, heart failure, valve disease, stroke, cancer)

Model 3: model 2 additionally adjusted for time-updated diabetes duration Model 3A: model 3 additionally adjusted for time-updated mean systolic blood pressure, time-updated mean body mass index, time updated smoking status, time-updated status about blood pressure lowering medication

Model 3B: model 3 additionally adjusted for time-updated mean high-density lipoprotein, time-updated mean low density lipoprotein, time-updated status about lipid lowering medication

Model 3C: Model 3 additionally adjusted for time-updated insulin method Model 3D: model 3 additionally adjusted for time-updated albuminuria categories

6.2 cases per 1000 person-years in controls [20]. The rates of coronary heart disease (CHD) events were 14.6 cases per 1000 person-years among patients with type 2 diabetes versus 8.7 cases per 1000 person-years among controls [21]. Additionally, 10.6 and 6.8 cases per 1000 person-years were diagnosed with stroke among individuals with and without type 2 diabetes, respectively [22]. The corresponding incidence for atrial fibrillation in the current study was 16.0 among individuals with type 2 diabetes compared to 11.9 among controls. Our study shows that atrial fibrillation is a common cardiovascular condition among persons with type 2 diabetes likely somewhat more common than with myocardial infarctions and heart failure.

The risk of atrial fibrillation among individuals with type 2 diabetes was also evaluated in relation to $1.0 \%$ $(10.0 \mathrm{mmol} / \mathrm{mol})$ higher mean HbA1c. HbA1c had a relatively modest impact on atrial fibrillation with a risk increase of $1.0-4.0 \%$ per $10 \mathrm{mmol} / \mathrm{mol}$ higher mean HbA1c compared to $12.0-19.0 \%$ for heart failure, acute myocardial infarction and CHD death [21, 23]. From these results, it can be concluded that the relative impact of glycaemic control on the risk of atrial fibrillation is relatively low compared with several other cardiovascular complications. From The Action to Control Cardiovascular Risk in Diabetes (ACCORD) trial, it was concluded that participants randomized to an intensive therapeutic strategy did not alter the rate of new-onset atrial fibrillation compared to participants randomized to a standard strategy [24]. Additionally, a study using a Mendelian randomization approach did not observe a causal role between type 2 diabetes and dysglycaemia on the development of atrial fibrillation [25]. However, it has been suggested that $\mathrm{HbA1c}$ variability might initiate atrial fibrillation in individuals with type 2 diabetes [26].

Since rates of diabetes mellitus and atrial fibrillation are increasing worldwide and are strong risk factors for stroke and cardiovascular mortality due to thromboembolic risk, it is important to consider early prevention. In a prospective observational study, cardiac rhythm abnormalities were common in patients with moderate to severe CKD not requiring dialysis [27]. Therefore, strategies to prevent renal complications with blood pressure control should be viewed as a goal for protection, both for renal and cardiovascular diseases. For instance, individuals with type 2 diabetes and blood pressure $<130 / 80 \mathrm{mmHg}$ had a risk of stroke similar to the general population [22]. Also, screening for atrial fibrillation before symptoms are manifested is important in certain patient populations. Clinicians should consider routine screening with pulse palpation or ECG rhythm strip in elderly persons with type 2 diabetes and those with renal complications. This could lead to early initiation of appropriate effective therapy, including antithrombotic therapy, to reduce the risk of stroke and death. Currently, there is no evidence that anti-diabetic therapies with glucagon-like peptide 1 (GLP-1) agonists, sodium-glucose cotransporter-2 (SGLT2) inhibitors nor dipeptidyl peptidase-4 (DPP4) inhibitor affect the development of atrial fibrillation [28].

The link between diabetes mellitus and atrial fibrillation may be explained by several possible mechanisms. The metabolic syndrome characterized by obesity, hypertension, insulin resistance, and dyslipidaemia has been 
proposed to be associated with increased risk of atrial fibrillation [29]. It has been hypothesized that metabolic syndrome causes a transformation of the epicardial adipose tissue leading to proinflammatory mediators causing endothelial dysfunction, and fibrosis, which in turn leads to the development of structural and electrical atrial remodelling [30-33]. In a nationwide populationbased study, body weight status and diabetes had synergistic effects on the risk of new-onset atrial fibrillation [34]. Animal studies confirms that insulin resistance was associated with various aspects of remodelling in the atria, proposing that these might share common electrical and structural remodelling processes in the atria [35].

Strengths of our study include the population-based design including the absolute majority of individuals with type 2 diabetes in Sweden. Additionally, well-known risk factors were available in persons with type 2 diabetes. Limitations include the absence of information on risk factors such as smoking, BMI, blood pressure, and lipid levels in the control population. Another limitation is that we cannot exclude the possibility that atrial fibrillation was detected to a somewhat higher extent in individuals with type 2 diabetes because it is a chronic disease requiring regular visits.

\section{Conclusion}

Type 2 diabetes remains a risk factor for atrial fibrillation, increasing risk by approximately $35 \%$ on a group level. Persons with advanced renal complications have substantially higher excess risks with a threefold excess risk at CKD-5. Glycaemic control likely has a relatively limited direct effect on the development of atrial fibrillation, but since it is essential for the development of renal complications it may have an effect over long time periods. Screening for atrial fibrillation should be considered in persons with increased risks including elderly and those with advanced renal complications among persons with type 2 diabetes, especially since the procedure is relatively simple.

\section{Supplementary information}

Supplementary information accompanies this paper at https://doi. org/10.1186/s12933-019-0983-1.

Additional file 1: Table S1. Cox regression for time to atrial fibrillationoverall, men and women. Table S2. Adjusted hazard ratios for atrial fibrillation and 95\% confidence intervals for time-updated mean HbA1c categories, albuminuria categories and eGFR categories versus the reference group examined by Cox regression-Men. Table S3. Adjusted hazard ratios for atrial fibrillation and 95\% confidence intervals for time-updated mean $\mathrm{HbA1c}$ categories, albuminuria categories and eGFR categories versus the reference group examined by Cox regression-Women. Table S4. Adjusted hazard ratios for atrial fribrillation and $95 \%$ confidence intervals for timeupdated mean $\mathrm{HbA} 1 \mathrm{c}$ categories together with albuminuria and eGFR versus the reference group examined by Cox regression-Men. Table S5.
Adjusted hazard ratios for atrial fibrillation and 95\% confidence intervals for time-updated mean $\mathrm{HbA1c}$ categories together with albuminuria and eGFR versus the reference group examined by Cox regression-Women. Table S6. The impact of time-updated mean HbA1c categories on time to first atrial fibrillation using Cox regression analysis among type 2 diabetes patients-Men. Table S7. The impact of time-updated mean HbA1c categories on time to first atrial fibrillation using Cox regression analysis among type 2 diabetes patients-Women.

\section{Abbreviations}

CHD: coronary heart disease; CKD: chronic kidney disease; HbA1c: glycated haemoglobin; HF: heart failure; HR: hazard ratio; IFCC: International Federation of Clinical Chemistry; IRR: incidence risk ratio; LDL: low-density lipoprotein; NDR: The Swedish National Diabetes Registry; NPR: The National Patient Registry.

\section{Acknowledgements}

The authors thank the regional NDR coordinators. Editorial assistance was provided by Joseph W. Murphy.

\section{Authors' contributions}

SSA wrote the first draft of the manuscript. SSA, ML, AP, AR and A-MS designed the study. AP performed statistical calculations; all authors took part in interpreting the data. All authors read and approved the final manuscript.

\section{Funding}

Open access funding provided by University of Gothenburg. This study was financed by grants from the Swedish State under an agreement between the Swedish government and the county councils concerning economic support for Research and Education of Doctors, Region Västra Götaland.

\section{Availability of data and materials}

Data are not publically available. Data may be available on request to the Swedish National Diabetes Registry.

\section{Ethics approval and consent to participate}

Ethical approval for this study was obtained from the Regional Ethical Review Board in Gothenburg, Sweden and was performed according to the Declaration of Helsinki. Patients gave informed consent that data in the Swedish National Diabetes are used for purposes related to diabetes research.

\section{Consent for publication}

Not applicable.

\section{Competing interests}

$M L$ has received research grants from DexCom and personal fees from Astra Zeneca, DexCom, Eli Lilly, Novonordisk and MSD. SSA, AR, AP and A-MS declare no competing interests.

\section{Author details}

${ }^{1}$ Department of Molecular and Clinical Medicine, University of Gothenburg, Gothenburg, Sweden. ${ }^{2}$ Department of Medicine, NU-Hospital Group, Trollhättan/Uddevalla, Sweden. ${ }^{3}$ Swedish National Diabetes Register, Centre of Registers, Gothenburg, Sweden. ${ }^{4}$ Statistiska Konsultgruppen, Gothenburg, Sweden. ${ }^{5}$ Department of Ophthalmology, Institute of Neuroscience and Physiology, Sahlgrenska Academy, University of Gothenburg, Gothenburg, Sweden. ${ }^{6}$ Sahlgrenska University Hospital, Gothenburg, Sweden.

Received: 28 September 2019 Accepted: 26 December 2019

Published online: 18 January 2020

\section{References}

1. Hameed I, Masoodi SR, Mir SA, Nabi M, Ghazanfar K, Ganai BA. Type 2 diabetes mellitus: from a metabolic disorder to an inflammatory condition. World J Diabet. 2015;6(4):598-612.

2. Zoni-Berisso M, Lercari F, Carazza T, Domenicucci S. Epidemiology of atrial fibrillation: European perspective. Clin Epidemiol. 2014;6:213-20. 
3. Zheng Y, Ley SH, Hu FB. Global aetiology and epidemiology of type 2 diabetes mellitus and its complications. Nat Rev Endocrinol. 2017;14:88.

4. Plitt A, McGuire DK, Giugliano RP. Atrial fibrillation, type 2 diabetes, and non-vitamin k antagonist oral anticoagulants: a review. JAMA Cardiol. 2017;2(4):442-8.

5. Movahed M-R, Hashemzadeh M, Mazen Jamal M. Diabetes mellitus is a strong, independent risk for atrial fibrillation and flutter in addition to other cardiovascular disease. Int J Cardiol. 2005;105(3):315-8.

6. Wilhelmsen L, Rosengren A, Lappas G. Hospitalizations for atrial fibrillation in the general male population: morbidity and risk factors. J Intern Med. 2001;250(5):382-9.

7. Benjamin EJ, Levy D, Vaziri SM, D’Agostino RB, Belanger AJ, Wolf PA. Independent risk factors for atrial fibrillation in a population-based cohort. Framingham Heart Study JAMA. 1994;271(11):840-4.

8. Huxley RR, Alonso A, Lopez FL, Filion KB, Agarwal SK, Loehr LR, et al. Type 2 diabetes, glucose homeostasis and incident atrial fibrillation: the atherosclerosis risk in communities study. Heart. 2012;98(2):133-8.

9. Zethelius B, Gudbjörnsdottir S, Eliasson B, Eeg-Olofsson K, Svensson A-M, Cederholm J. Risk factors for atrial fibrillation in type 2 diabetes: report from the Swedish National Diabetes Register (NDR). Diabetologia. 2015;58(10):2259-68.

10. Aune D, Feng T, Schlesinger S, Janszky I, Norat T, Riboli E. Diabetes mellitus, blood glucose and the risk of atrial fibrillation: a systematic review and meta-analysis of cohort studies. J Diabet Complicat. 2018;32(5):501-11.

11. Lane DA, Lip GY. Use of the CHA(2)DS(2)-VASc and HAS-BLED scores to aid decision making for thromboprophylaxis in nonvalvular atrial fibrillation. Circulation. 2012;126(7):860-5.

12. Levey AS, Eckardt KU, Tsukamoto Y, Levin A, Coresh J, Rossert J, et al. Definition and classification of chronic kidney disease: a position statement from Kidney Disease: Improving Global Outcomes (KDIGO). Kidney Int. 2005;67(6):2089-100.

13. Dahlqvist S, Rosengren A, Gudbjornsdottir S, Pivodic A, Wedel H, Kosiborod M, et al. Risk of atrial fibrillation in people with type 1 diabetes compared with matched controls from the general population: a prospective case-control study. Lancet Diabet Endocrinol. 2017;5(10):799-807.

14. Huxley RR, Filion KB, Konety S, Alonso A. Meta-analysis of cohort and case-control studies of type 2 diabetes mellitus and risk of atrial fibrillation. Am J Cardiol. 2011:108(1):56-62.

15. Pallisgaard JL, Schjerning AM, Lindhardt TB, Procida K, Hansen ML, Torp-Pedersen C, et al. Risk of atrial fibrillation in diabetes mellitus: a nationwide cohort study. Eur J Prev Cardiol. 2016;23(6):621-7.

16. Schoen T, Pradhan AD, Albert CM, Conen D. Type 2 diabetes mellitus and risk of incident atrial fibrillation in women. J Am Coll Cardiol. 2012;60(15):1421-8

17. Ostgren CJ, Merlo J, Rastam L, Lindblad U. Atrial fibrillation and its association with type 2 diabetes and hypertension in a Swedish community. Diabet Obes Metab. 2004;6(5):367-74

18. Miyake H, Kanazawa I, Sugimoto T. Albuminuria Increases all-cause mortality in japanese patients with type 2 diabetes mellitus. J Clin Med. 2018;7(9):234

19. Anyanwagu U, Donnelly $R$, Idris I. Albuminuria regression and all-cause mortality among insulin-treated patients with type 2 diabetes: analysis of a large UK primary care cohort. Am J Nephrol. 2019:49(2):146-55.

20. Rosengren A, Edqvist J, Rawshani A, Sattar N, Franzen S, Adiels M, et al. Excess risk of hospitalisation for heart failure among people with type 2 diabetes. Diabetologia. 2018;61(11):2300-9.
21. Tancredi M, Rosengren A, Svensson AM, Pivodic A, Gudbjornsdottir S, Wedel $\mathrm{H}$, et al. Glycaemic control and excess risk of major coronary events in patients with type 2 diabetes: a population-based study. Open Heart. 2019;6(2):e000967.

22. Hedén Ståhl C, Lind M, Svensson AM, Kosiborod M, Gudbjörnsdottir S, Pivodic A, et al. Long-term excess risk of stroke in people with Type 2 diabetes in Sweden according to blood pressure level: a population-based case-control study. Diabet Med. 2017;34(4):522-30.

23. Lind M, Olsson M, Rosengren A, Svensson AM, Bounias I, Gudbjörnsdottir S. The relationship between glycaemic control and heart failure in 83,021 patients with type 2 diabetes. Diabetologia. 2012;55(11):2946-53.

24. Fatemi O, Yuriditsky E, Tsioufis C, Tsachris D, Morgan T, Basile J, et al. Impact of intensive glycemic control on the incidence of atrial fibrillation and associated cardiovascular outcomes in patients with type 2 diabetes mellitus (from the Action to Control Cardiovascular Risk in Diabetes Study). Am J Cardiol. 2014;114(8):1217-22.

25. Harati H, Zanetti D, Rao A, Gustafsson S, Perez M, Ingelsson E, et al. No evidence of a causal association of type 2 diabetes and glucose metabolism with atrial fibrillation. Diabetologia. 2019;62(5):800-4.

26. Gu J, Fan YQ, Zhang JF, Wang CQ. Impact of long-term glycemic variability on development of atrial fibrillation in type 2 diabetic patients. Anatolian J Cardiol. 2017;18(6):410-6.

27. Akoum N, Zelnick LR, de Boer IH, Hirsch IB, Trence D, Henry C, et al. Rates of cardiac rhythm abnormalities in patients with CKD and diabetes. Clin J Am Soc Nephrol CJASN. 2019;14(4):549-56.

28. Bell DSH, Goncalves E. Atrial fibrillation and type 2 diabetes: prevalence, etiology, pathophysiology and effect of anti-diabetic therapies. Diabetes Obes Metab. 2019;21(2):210-7.

29. Watanabe H, Tanabe N, Watanabe T, Darbar D, Roden DM, Sasaki S, et al. Metabolic syndrome and risk of development of atrial fibrillation: the Niigata preventive medicine study. Circulation. 2008;117(10):1255-60.

30. Packer M. Disease-treatment interactions in the management of patients with obesity and diabetes who have atrial fibrillation: the potential mediating influence of epicardial adipose tissue. Cardiovasc Diabetol. 2019;18(1):121.

31. Grisanti LA. Diabetes and arrhythmias: pathophysiology, mechanisms and therapeutic outcomes. Front Physiol. 2018;9:1669.

32. Karam BS, Chavez-Moreno A, Koh W, Akar JG, Akar FG. Oxidative stress and inflammation as central mediators of atrial fibrillation in obesity and diabetes. Cardiovasc Diabetol. 2017:16(1):120.

33. Tadic M, Cuspidi C. Type 2 diabetes mellitus and atrial fibrillation: from mechanisms to clinical practice. Archiv Cardiovasc Dis. 2015;108(4):269-76

34. Kim YG, Han KD, Choi Jl, Boo KY, Kim DY, Oh SK, et al. The impact of body weight and diabetes on new-onset atrial fibrillation: a nationwide population based study. Cardiovasc Diabetol. 2019;18(1):128.

35. Chan YH, Chang GJ, Lai YJ, Chen WJ, Chang SH, Hung LM, et al. Atrial fibrillation and its arrhythmogenesis associated with insulin resistance. Cardiovasc Diabetol. 2019:18(1):125.

\section{Publisher's Note}

Springer Nature remains neutral with regard to jurisdictional claims in published maps and institutional affiliations.

Ready to submit your research? Choose BMC and benefit from:

- fast, convenient online submission

- thorough peer review by experienced researchers in your field

- rapid publication on acceptance

- support for research data, including large and complex data types

- gold Open Access which fosters wider collaboration and increased citations

- maximum visibility for your research: over 100M website views per year

At BMC, research is always in progress.

Learn more biomedcentral.com/submissions 